\title{
A large-Scale Study on Extensive Reading Program for Non- English Majors: Factors and Attitudes
}

\author{
Ching-Yi Tien \\ Department of Applied Enlgish, I-Shou University \\ No.1, Sec. 1, Syuecheng Rd. Dashu District, Kaohsiung City 84001, Taiwan \\ E-mail: t2929@ms9.hinet.net
}

Received: 16-11- 2014

Published: 01-07- 2015
Accepted: 26-01- 2015

doi:10.7575/aiac.ijalel.v.4n.4p.46
Advance Access Published: February 2015

URL: http://dx.doi.org/10.7575/aiac.ijalel.v.4n.4p.46

The research is financed by Ministry of Education, Taiwan. ISU102-T-001A.

\begin{abstract}
Reading is a complex method of drawing information from some form of text and then interpreting it. The importance of reading in an academic context cannot be underestimated in its influence on learning. It is commonly agreed that students should read extensively in order to enhance their reading skills and to learn other knowledge through that reading. This paper presents an analysis of teachers' and students' perceptions toward an extensive reading program located in an EFL higher education context. Particularly, the study aims at assessing factors that may influence the students' attitudes toward extensive reading (ER) and both students' and teachers' perceptions to the newly implemented extensive reading program. In this paper, the author attempts to analyze and understand the effectiveness of an extensive reading program. The results show that: first, differing majors among students and the amount of time spent weekly on reading graded readers directly impacts students' attitudes toward extensive reading. Second, although many students verbally express a dislike for ER programs in class, they strongly agree that ER is a good way to learn English on the survey. Third, in spite of teachers' skepticism prior to the ER program, results confirm the linguistic benefit ER brought to learners upon completion of the program. Notwithstanding the preliminary resistance of the ER program, teachers' and students' attitudes noticeably changed over the two semesters of engagement.
\end{abstract}

Keywords: extensive reading, perceptions, attitudes, EFL, higher education

\section{Introduction}

Owing to the trend of globalization, the need of using and learning English is ubiquitous; so, Taiwan has proven to be no exception. Although Grades 1-9 Curriculum was been promulgated by the Ministry of Education, Taiwan has indicated that English be taught as compulsory EFL coursework beginning in the fifth grade. As a result, most Taiwanese elementary schools have made their own rules to require their students to start learning English from grade three. In other words, by the time students attend colleges or universities, they should have already received at least nine years of English education. Yet, based on the Worldwide Report 2013 published by ETS (2014), the average Taiwanese test taker scored 569, a little bit higher than Japan's (512), but lower than Korea's (632) and Hong Kong's (644). When looking more closely at the overall scores, the average score for the reading section of the Taiwanese test takers is 263 (the full score being 495) which arouses a great discussion on which teaching method provides better language learning and teaching outcomes respective of reading.

There has even been great debate on the promotion of the Communicative Approach in Taiwan's English teaching and learning context; however, most instructors still rely heavily on the Grammar Translation Method due to the pressure of getting students passing all kinds of English language assessment. This is especially true in light of the localized high school and university entrance exams. Consequently, the majority of students become good test takers, but they do not become good readers. The Ministry of Education in Taiwan has stipulated a new language policy which now requires university students to reach a certain English proficiency level prior to matriculation in hopes of enhancing students' overall English ability. Although the original intention may be good, it has made the English learning environment become exceedingly test-centered. Inadequate training for comprehensive reading in English is ubiquitous, and it indirectly influences students' habits and attitudes toward English reading in general. Additionally, although the importance and benefits of extensive reading have been highly recognized, it has been "excluded from the English teaching syllabuses" (Sheu 2004, p. 214).

In view of this predicament, and to direct students away from reading solely for test purposes, the extensive reading project of the research site was first proposed and then established to better develop students' habits towards reading extensively and even further develop students' abilities to read fluently in English outside the classroom.

\section{Theoretical review}

Reading is a complex method of drawing information from some form of text and then interpreting it. Readers can choose a variety of skills and strategies depending on the purpose of the reading and create their own overall reading comprehension depending on individual language proficiency (Grabe \& Stoller, 2002). Reading for general comprehension involves skills that represent linguistic abilities (e.g. word recognition, syntactic processing, etc.) and 
defined strategies that are implemented by the readers themselves. Although the definitional boundaries of skills and strategies are imprecise because of the nature of reading tasks, strategies may be seen as "skills under consideration" (Paris, Wasik, \& Turner, 1991, p. 611).

\subsection{Extensive reading}

In addition to the massive studies on reading skills and strategies already in the literature, much attention has also been paid to the effectiveness/ benefits of extensive reading. The growing amount of research supporting the use of extensive reading includes studies concerning young learners (Juan \& Cheng, 2008; Nishino, 2007; Williams, 2007), adult learners (Greenberg et al, 2006; Renandya et al, 1999), vocabulary building (Horst, 2005; Kweon \& Kim, 2008; Pigada \& Schmitt, 2006; Modirkhamene \& Gowrki, 2011; Tran, 2006), reading habits (Asraf \& Ahmad, 2003; Lemmer, 2010), reading speed and comprehension (Bell, 2001; He, 2014; Taguchi, et al, 2004), writing performance (Mason \& Krashen, 1997), and reading ability (Meng, 2009; Robb \& Susser, 1989; Sheu, 2004; Yamashita, 2008). Significantly, there is also a substantial number of studies stressing students' positive attitudes (Camiciottoli, 2001; Johanson, 2012; Shen, 2008; Stoeckel et al, 2012) and motivations (Apple, 2005; Mason \& Krashen; Takase, 2007) towards the extensive reading process after the treatment. The list is not exhaustive.

A study done by Yamashita (2013) examined the effects of extensive reading attitudes among 61 undergraduates who were teaching and learning English as a foreign language at a Japanese university after 15 weeks of course implementation with extensive reading. The results have shown that ER had a stronger effect on enhancing positive feelings than of reducing negative feelings; resultantly, ER may help the learners to develop their language skills as well as to expand their general knowledge base. ER may also serve to promote learner autonomy and reading enjoyment in a learning context. Robb and Kano (2013) also reported on a large-scale basis regarding an implementation of extensive reading in a Japanese university which required students to read graded readers outside of classroom as part of their course requirements. The study compared students who did extensive reading as additional coursework needed to achieve better reading scores than the students who were not required to do so. Results proved that the presence of an extensive reading approach was the main factor for higher score improvement as part of this study.

\subsection{Graded readers}

In most of the extensive reading programs, graded readers seem to be the preferred materials chosen by the practitioners for the reason that they are not merely a source of reading for pleasure but a good source for language learning. As Hill (2001) stated, graded readers assist learners in four important ways:

1. They motivate.

2. They help develop the skill of reading fluently (e.g. at 200 words or more per minute).

3. They help language learning by providing a context for language that enhances and extends the learner's understanding of both lexis and syntax.

4. They offer a more accessible source of exposure to target syntax. (pp. 301-2)

Hill (ibid) also stressed that skills found in fluent reading and increased reading speed can be developed through regular practice with graded readers for the sole reason that it gives learners more exposure to the target language.

The most salient feature of graded readers is its simplified text. Although advocates firmly believe that language learners can be encouraged to read more extensively by reading simplified text, the question of how to choose the appropriate text is still not well answered. Honeyfield (1977) examined the appropriateness and effectiveness of traditional simplification techniques (e.g. using graded readers) to prepare students for a smooth and orderly progression to full English. He suggested that although simplified text has its advantage to help learners in language learning, for intermediate and advanced students, it is better to encourage these groups of students to embark upon reading unsimplified, original-source material. A study done by Maruyama (2009) discussed the importance of graded readers and on how to decide which graded-reader's level to assign to students by using a Vocabulary Level Test. Results showed that this approach is an effective tool useful for selection of suitable readers appropriate to the readers' level. Schmitt and Schmitt (2014) conducted a study to investigate whether a particular series of graded readers could provide a bridge for students to read unsimplified novels for pleasure. The results suggested that it is possible for motivated readers to read from the highest-graded readers to carefully-selected, ungraded novels.

Studies that are demonstrated above have indicated the various benefits of adopting extensive reading in pedagogical contexts. However, the implementation of ER program in Taiwan still requires exploration especially among large-scale studies. Hence, the following research questions were posed at the outset of the study:

1. What factors influence the students' attitudes toward extensive reading?

2. What are the students' perceptions toward the extensive reading program?

3. What are the instructors' perceptions toward the extensive reading program?

\section{Methodology}

This research is part of a larger study of an ISU-Teaching Excellence Project funded by the Ministry of Education, Taiwan, with special attention to the newly implemented extensive reading program made available to non-English majors. This is a two-year program and the current study is conducted at the end of the first year to evaluate the outcome of the program's overall standing.

\subsection{Participants}

This study was conducted during fall 2013 and spring 2014 semesters. It involved both freshman and sophomore students who were taking General English courses from a private university in southern Taiwan. There were a total of 93 classes, 5,711 students who were from eight different colleges. A total of 16 full-time and 20 part-time instructors were also involved as part of this study. The classroom instruction lasted two-hours per week for a period of 18 weeks per semester. The treatment for the current study lasted for two semesters which were made up of a total of 36 weeks. 
In order to investigate the non-English major Taiwanese university students' attitudes toward extensive reading in English, two questionnaires (one for the students, one for the instructors ) originally designed by Morgado (2009) with modification to meet the purpose of the research were used, and a subsequent focus-group interview was conducted. The student questionnaire consisted of four sections: section one provided for the demographic information; section two had twenty item questions based on a five point summated Likert-type response, ranging in scale from 5 (strongly agree) to 1, (strongly disagree), and the items are subdivided into four specified categories: general opinions (7 items), enjoyment ( 3 items), reading proficiency (6 items), thinking ability (4 items); section three was made up of four overall (e.g. aggressive attitude, autonomous reading habits, great pleasure, and linguistic improvement) true(1) / false(2) questions; and, the last section was an open-ended question available for students to express any concerns they may have regarding extensive reading. The modified questionnaire showed an internal consistency coefficient of .938 (Cronbach's alpha, $n=24$ ). The focus-group interview was conducted at the end of the current study to probe and confirm students' comments made in the online survey. Items in the teacher questionnaire are similar to those of the students' with a few questions specifically modified for the instructors. The internal consistency coefficient of .858 (Cronbach's alpha, $n=24$ ). Four meetings were conducted with the instructors involved to discuss and evaluate the extensive reading program.

\subsection{Procedure}

Thirty-six instructors and 5,711 students were recruited for the present study. Students were enrolled during the fall 2013 and spring 2014 semesters. The courses met two-hours per week for a total of 36 weeks. In class, intensive reading was practiced; however, outside of the class, students were required to read four graded readers during each semester, for a total of eight readers in two semesters. To decide how many graded readers should be read per semester, Nation (2001) suggested for learners to read a book weekly or in two weeks' time; Maruyama (2009) asked the participants to read five graded readers in one semester; and Cetin and Brooks- Lewis (2011) requested the students to read six readers. Based on a pilot study the researcher had conducted, she was astonished to find out that nearly ninety percent of her university students did not have any outside reading experience to speak of. Considering the current study is a newlyimplemented extensive reading program available to a large number of students, reading four graded readers per semester was determined to be the optimal number. Having considering the number of readers for the students to complete reading, the next issue was who would choose what books to read. Although there are studies suggesting having students to self-select their own reading materials for enjoyment (Paulson, 2006), or for students to be given an opportunity to choose the books they preferred (Asraf \& Ahmad, 2003), the researcher was acutely aware of the fact that it was better to give permission to the instructors to decide which readers meets their students' needs to insure task compliance. The readers adopted for this program were mainly graded readers from the Cambridge, Oxford, Penguin, Longman, Heinemann, Compass Publishing, and Scholastic series, with basal reader levels ranging from two to five. Completion of the reading assignment accounted for 10 percent of the student's overall class grade for each semester. Approximately 600 titles of the readers were purchased and kept in the library available at all times for students who did not wish to buy their own books to use at any time.

To begin with, the extensive reading project precipitated four meetings. The purpose of the first meeting was to inform and explain this project to the instructors regarding its aims, objectives, and ideal outcomes. In the initial meeting, more than half of the experienced instructors doubted the possibility of improvement in the students' English proficiency and relative change of attitudes for engaging in outside readings. A couple of instructors strongly disagreed with the feasibility of launching this project. To ensure both teacher and students participants were taking part in the extensive reading program; a second meeting was conducted in the half-term of fall semester 2013. Unsurprisingly, some instructors ignored the extensive reading program initiative completely and neither introduced nor asked the students to address the readers. Hence, the determination of completing the project and promoting the extensive reading was reemphasized in a second meeting and the methods for evaluation were further discussed. To be mentioned, the first year of the project focuses on promotion and development of students' habits to read extensively (here, meaning graded readers); hence, instructors were given the freedom to adopt any formats to assess students' reading performance. The third and fourth meetings were conducted in the second semester to examine the outcome of the program.

\section{Findings}

Three research questions are explored in the study. 1. What factors influence the students' attitude toward extensive reading? 2. What are the students' perceptions toward the extensive reading program? 3. What are the instructors' perceptions toward the extensive reading program? To answer these questions, an anonymous online question was posted for students to respond; 1,583 out of 5,711 participants completed the survey successfully. The low response rate (28\%) may be explained in two ways: first, in order to complete survey, participants must answer every question in the questionnaire. Some students quit the survey when he/she encountered the open-ended questions; this was confirmed during the focus-group interview. Such conduct invalidated the survey. The second aspect to consider might be that it was on a voluntary basis, meaning that some students may not have wished to be bothered with this extra task of survey completion. Despite this inherent criticism, the sample size of 1,583 is considered to be sufficient for purposes of this study. Descriptive statistics are summarized and reported in the following sections.

4.1 Answer to the first research question

The first research question in this study, "What factors influence the students' attitude toward extensive reading?", is posed to investigate factors that may influence students' attitudes toward extensive reading. To this end, the modified survey form was adopted. To examine whether gender was one of the influential factors, independent-samples t-test was computed. The results in Table 1 indicate that gender plays a significant role in extensive reading. 
Table 1. t-test Results Comparing Male and Female Attitudes in Four Categories

\begin{tabular}{lllllll}
\hline Categories & Gender & $N$ & Mean & $S D$ & $t$ & Sig.(2-tailed) \\
\hline General opinion & Male & 706 & 3.95 & .86 & 2.034 & .042 \\
& Female & 877 & 3.86 & .78 & & \\
Enjoyment & Male & 706 & 3.76 & .94 & 2.986 & .003 \\
& Female & 877 & 3.64 & .89 & & \\
Reading proficiency & Male & 706 & 4.00 & .83 & 2.589 & .010 \\
& Female & 877 & 3.80 & .76 & & \\
Thinking ability & Male & 706 & 3.85 & .89 & 2.734 & .006 \\
& Female & 877 & 3.73 & .83 & & \\
Overall & Male & 706 & 1.32 & .36 & -1.672 & .095 \\
& Female & 877 & 1.35 & .33 & & \\
\hline
\end{tabular}

As Table 1 shows that both male and female students in the study held considerably different attitudes toward extensive reading in terms of general opinion $[t(1433.623)=2.034, p=.042]$, enjoyment $[t(1466.866)=2.986, p=.003]$, reading proficiency $[t(1582)=2.589, p=.010]$, thinking ability $[t(1457.437)=2.743, p=.006]$, and overall $[t(1534.910)=-2.558$, $p=.011]$. It is interesting to note that the mean scores reveal that male students are slightly more positive in their attitude than female students toward extensive reading. Regarding the means related to general opinion, male is 3.95 and female is 3.86; the means on enjoyment, male is 3.76 and female is 3.64 ; the means on reading proficiency, male is 4.00 and female is 3.80; the means on thinking ability, male is 3.85 and female is 3.73 ; and, the means for overall items, male is 1.32 and female is 1.35 (true(1)/ false(2)). For the category of overall evaluation questions (having a positive attitude, building up an autonomous reading habit, having great pleasure, linguistic improvement), only the item regarding my English has improved by the mean of extensive reading reveals a significant difference, $t(1534.910)=-2.558, p=.011$.

To further investigate whether the student's year of study (freshman, sophomore, junior, and senior), the level of English classes (beginner, intermediate, and advanced), different colleges (College of Electrical and Information Engineering, College of Science and Engineering, College of Management, College of Communication and Design, International College, College of Tourism and Hospitality, College of Language Arts, College of Medicine), and time spent weekly (less than one hour, 1 to 4 hours, 4 to 6 hours, and more than 6 hours) for extensive reading were factors for students to be engaged in extensive reading, one-way ANOVA was conducted. An analysis of variance showed that the year of study was not significant, apart from item 28 (I have built up an autonomous reading habit through extensive reading.), $F(3,1579)=3.165, p=.024$. The level of English classes also showed no significance at all, $p>.005$.

Table 2. One-way ANOVA Analysis for the Variable of Colleges

\begin{tabular}{lllllll}
\hline Categories & & $S S$ & $d f$ & $M S$ & $F$ & Sig. \\
\hline General & Between groups & 22.277 & 6 & 3.713 & 5.682 & .000 \\
& Within groups & 1029.806 & 1576 & .653 & & \\
& total & 1052.083 & 1582 & & & \\
\hline Enjoyment & Between groups & 30.797 & 6 & 5.133 & 6.264 & .000 \\
& Within groups & 1291.492 & 1576 & .819 & & \\
& total & 1322.288 & 1582 & & & \\
\hline Reading & Between groups & 17.700 & 6 & 2.950 & 4.747 & .000 \\
proficiency & Within groups & 979.458 & 1576 & .621 & & \\
& total & 997.158 & 1582 & & & \\
\hline Thinking & Between groups & 29.580 & 6 & 4.930 & 6.852 & .000 \\
ability & Within groups & 1133.998 & 1576 & .720 & & \\
& total & 1163.578 & 1582 & & & \\
\hline Overall & Between groups & 2.677 & 6 & .446 & 3.430 & .002 \\
& Within groups & 204.943 & 1576 & .130 & & \\
& total & 207.619 & 1582 & & & \\
\hline
\end{tabular}

Note: $S S=$ sum of squares, $M S=$ mean square, ${ }^{*} p<.05,{ }^{* *} p<.01,{ }^{* * *} p<.001$

To understand whether students' inclusion in one of the eight different colleges (different majors) made a significant difference toward extensive reading practices and perceptions, a one-way ANOVA was applied. Results are displayed in the Table 2 showing that general opinion $[F(6,1576)=5.682, p=.000]$, enjoyment $[F(6,1576)=6.264, p=.000]$, 
reading proficiency $[F(6,1576)=4.747, p=.000]$, thinking ability $[F(6,1576)=6.852, p=.000]$, and overall $[F(6$, $1576)=3.430, p=002]$ all reach a very significant level of .001 and the last one .01 . Thus, there are significant differences of perceptions among students from the eight colleges regarding extensive reading practices. Post hoc analyses using the Scheffé post hoc criterion shows that there is significant difference between some pair of means. Particularly, by comparing the means of these pairs, the results indicate that students from College of Management $(M=4.08, S D=.818)$ were general more positively disposed about ER than College of Science and Engineering $(M=3.82$, $S D=.811)$, College of Medicine $(M=3.81, S D=.806)$, and College of Communication and Design $(M=3.77, S D=.760)$. College of Management $(M=3.88, S D=.963)$ enjoyed ER more than College of Medicine $(M=3.57, S D=.922)$ and College of Communication and Design $(M=3.53, S D=.807)$. College of Management $(M=4.11, S D=.796)$ firmly believed that ER helps to increase their reading proficiency more than College of Medicine $(M=3.86, S D=.775)$ and College of Communication and Design $(M=3.78, S D=.768)$. Agreeing that ER fosters students' thinking ability, College of Management $(M=3.96, S D=.923)$ is higher than College of Electrical and Information Engineering $(M=3.93$, $S D=.818)$, College of Medicine $(M=3.70, S D=.844)$ and College of Communication and Design $(M=3.55, S D=.807)$. Overall in speaking, the College of Management $(M=1.28, S D=.366)$ is more positively disposed towards the ER program than the College of Medicine $(M=1.37, S D=.359)$.

Additionally, the factor of time spent weekly for purposes of extensive reading was also examined via a one-way analysis of variance (ANOVA). The statistical results are presented in Table 3.

Table 3. One-way ANOVA Analysis for the Variable of Time Spent Weekly

\begin{tabular}{lllllll}
\hline Categories & & $S S$ & $d f$ & $M S$ & $F$ & Sig. \\
\hline General & Between groups & 54.115 & 3 & 18.038 & 28.540 & .000 \\
opinion & Within groups & 997.968 & 1579 & .632 & & \\
& total & 1052.083 & 1582 & & & \\
\hline Enjoyment & Between groups & 59.117 & 3 & 19.706 & 24.633 & .000 \\
& Within groups & 1263.171 & 1579 & .800 & & \\
& total & 1322.288 & 1582 & & & \\
\hline Reading & Between groups & 37.065 & 3 & 12.355 & 20.320 & .000 \\
proficiency & Within groups & 960.093 & 1579 & .608 & & \\
& total & 997.158 & 1582 & & & \\
\hline Thinking & Between groups & 40.117 & 3 & 13.372 & 18.795 & .000 \\
ability & Within groups & 1123.461 & 1579 & .712 & & \\
& total & 1163.578 & 1582 & & & \\
\hline Overall & Between groups & 14.434 & 3 & 4.811 & 39.326 & .000 \\
& Within groups & 193.185 & 1579 & .122 & & \\
& total & 207.619 & 1582 & & & \\
\hline
\end{tabular}

Note: $S S=$ sum of squares, $M S=$ mean square, ${ }^{*} p<.05,{ }^{* *} p<.01,{ }^{* * *} p<.001$

Results demonstrated in the Table 3 indicate that general opinion $[F(3,1579)=28.540, p=.000]$, enjoyment $[F(3$, $1579)=24.633, p=.000]$, reading proficiency $[F(3,1579)=20.320, p=.000]$, thinking ability $[F(3,1579)=18.795, p=$ $.000]$, and overall $[F(3,1579)=39.326, p=000]$ all reach a significant level of .001 . Thus, how much time students spent for reading readers is also a significant factor. A Post Hoc Test Scheffe test and comparison of the means of the significant pairs found in the results points out those students who spent four to six hours per weeks strongly agreed with the ER program's implementation.

\subsection{Answer to the second research question}

The second question needing to be address is "What are the students' perceptions toward the extensive reading program?" To answer this question, the top five statements agreed to by the student participants are listed and students' written comments are also provided for further clarification. Generally speaking, students' perceptions toward extensive reading, apart from true(1)/false(2) items, are quite positive for the average mean is 3.83 on a 5-point Likert scale. 
Table 4. The Top-5 Statements Supported by the Students of Extensive Reading

\begin{tabular}{lll}
\hline Statements & Mean & $S D$ \\
\hline Q8. I think ER is a good way to learn English. & 4.14 & .780 \\
Q7. I think it is important to do ER. & 4.01 & .852 \\
Q18. Through ER, my reading comprehension improved. & 3.98 & .831 \\
Q20. Through ER, it enriches my vocabulary. & 3.98 & .839 \\
Q21. Through ER, it my word recognition developed. & 3.97 & .847 \\
\hline
\end{tabular}

Note: $N=1,583$

As Table 4 indicates that the Top-5 statements students agreed on are: first, ER is a good way to learn English ( $M=4.14$, $S D=.780)$; second, it is important to do ER $(M=4.01, S D=.852)$; third, ER helps to improve reading comprehension $(M=3.98, S D=.831)$; fourth, ER enriches students' vocabulary $(M=3.98, S D=.839)$, and the fifth, ER helps to develop word recognition $(M=3.97, S D=.847)$. For true(1) / false(2) items, students reported that ER helps to develop a reading habit $(M=1.15, S D=.359)$. However, students did choose to report that their attitudes toward ER were not active $(M=1.46, S D=.499)$, and they did not really enjoy doing ER $(M=1.40, S D=.491)$.

Due to the limited space in this paper, the results of the focus group interview data and the open-ended questions are combined and reported as follows. The open-ended question of the questionnaire asked students to express any concerns they may have regarding extensive reading, all 1,583 responses can be generally categorized into: no comments (860), moderate comments (370), very good comments (206), and negative comments (147). The moderate comments that students expressed are: for example, it is good/ interesting to read the readers; it helps to improve my English/reading comprehension; some suggested reading on more different topics or allow students to choose the books they preferred. For very good comments, students specifically pointed out that by reading the readers, their vocabulary size increased; the reading fluency / speed increased; some suggested to read more; some thought it is better than doing test-preparation type of reading; some strongly supported reading the readers but suggested to have various evaluation formats made available; and, many suggested to read the movie version of the readers' content. The negative comments are: it is expensive to buy four readers; it is too difficult to read (lots of unknown words); it is meaningless to read readers without assistance from the instructors; some reported that they are too busy with their other academic subjects, so they have no time for the readers; the time provided for reading the readers was insufficient; therefore, the students cannot really enjoy reading the readers; and, some students preferred to read articles from ESL / EFL language magazines rather than from readers.

\subsection{Answer to the third research question}

The third research question of this study is "What are the instructors' perceptions toward the extensive reading program?" As mentioned previously, although the instructors involved in this study acknowledge the benefits of extensive reading, they still remained skeptical about the feasibility of launching such program at the researched university due to the limited teaching hours available and the demotivated nature of the students involved. After four meetings in which such concerns were openly discussed, some instructors gradually expressed their support for the ER program. To better understand the instructors' perceptions toward the program, a 24-items questionnaire (Section A: items 1 to 16; Section B: items 17 to 24) items along with one open-ended question was distributed to 36 instructors; 32 surveys were successfully completed and collected. The descriptive statistics reveal that the means for Section A is 4.18 (on the 5-point Likert scale) and the means for Section B is 1.29 (true(1) / false(2)). These results demonstrate that instructors were considered to be highly positive about the extensive reading by the end of the program. In order to compare responses according to gender-type, the independent-samples t-test was computed. The result illustrates that male and female instructors held considerable different perceptions toward extensive reading specifically in the category of thinking ability $[t(23.000)=-2.598, p=.016]$. Male instructors $(M=1.00, S D=.000)$ are slightly more approving than female instructors $(M=1.15, S D=.275)$ to the notion that students built up their critical thinking skills through the practice of extensive reading.

To understand what the instructors most agreed upon in the program, the top six items from Section A and the top three items Section B are then presented respectively.

Table 5. The Top 6 Items from Section A Supported by the Instructors of Extensive Reading

\begin{tabular}{lcc}
\hline Items & Mean & SD \\
\hline $\begin{array}{l}\text { Q1. I think outside readers are important for students in learning } \\
\text { English. }\end{array}$ & 4.563 & .564 \\
Q2. I think outside readers are one of the methods for learning English. & 4.531 & .671 \\
Q5. Reading outside readers is one of the good ways to help students to build up reading 4.438 & .669 \\
$\quad$ habits. & 4.406 & .712 \\
Q3. I will continually ask my students to read outside readers. & 4.406 & .712 \\
Q4. Reading outside readers will help students to build up reading habits. & 4.406 & .615 \\
Q6. Reading outside readers will help students to build up reading fluency. &
\end{tabular}

Note: $N=32$ 
The results of teacher responses for the Section A seem to be significantly more positive for the extensive reading. Particularly, teachers were most agreed upon that the use of outside readers are important for students to learn English (Q1, $M=4.563, S D=.564)$. This is followed by the statement which indicates that the use of outside readers is one of the recognized methods for learning English (Q2, $M=4.531, S D=$

.671). Additionally, teachers exceedingly agreed upon the notion that engaging students with outside readers is not only a good method (Q5, $M=4.438, S D=.669)$, but it will also help students to develop their reading habits $(\mathrm{Q} 4, M=4.406$, $S D=.712)$ and reading fluency $(\mathrm{Q} 6, M=4.406, S D=.615)$. More importantly, the responses to whether or not teachers will continually ask for their students to read outside readers (Q3, $M=4.406, S D=.712$ ) should be noted.

Table 6. The Top 3 Items from Section B Supported by the Instructors of Extensive Reading

\begin{tabular}{lll}
\hline Items & Mean & SD \\
\hline Q19. Students learn more about different cultures through outside readers. & 1.031 & .177 \\
$\begin{array}{l}\text { Q20. Students will be able to see things from different perspectives though reading outside } 1.063 \\
\text { readers. }\end{array}$ & .246 \\
$\begin{array}{l}\text { Q24. Overall speaking, students' English proficiency will be improved through reading } 1.094 \\
\quad \text { outside readers. }\end{array}$ & .296 \\
\hline
\end{tabular}

Note: $N=32 ;$ true $=1$, false $=2$.

Table 6 presents the statistical results of the top 3 items from Section B supported by the instructors of extensive reading. When compared with the enthusiastically positive support evidenced from Section A, the teachers' overall evaluation for the extensive reading program is somewhat moderate. Yet, teachers did agree that, through the use of outside readers, students are able to learn more about different cultures $(\mathrm{Q} 19, M=1.031, S D=.177)$, and they are able to see things from different perspectives (Q20, $M=1.063, S D=.246)$. Teachers also supported that students' English proficiency will be improved through the reading of outside readers (Q24, $M=1.094, S D=.296$ ).

Teachers' spoken comments made in the meetings and the responses to the open-ended questions are combined and highlighted as follows. The positive comments are: "1) Extensive reading is a good way to help students to improve their English". "2) Students will know more vocabulary through extensive reading". "3) Students in the higher level English classes enjoyed ER more than those in the lower level classes". And, "4) we should keep running the ER program". However, there were also some negative comments offered from the teachers, such as: "Cut down the number of readers"; "Ask students to read short articles instead of readers"; and, students don't want to buy the readers. One of the teachers even worried that if $\mathrm{s} / \mathrm{he}$ forced the students to buy readers, students might think that the teacher is trying to make a profit from the publishers' commissions.

\section{Discussion and conclusion}

This study aims at examining factors that may influence non-English major students' attitudes toward extensive reading (ER) and both students' and teachers' perceptions of the newly implemented extensive reading program. Both qualitative and quantitative data have shown that although there is some resistance among teachers and students at the beginning of the program, after two semesters of involvement with reading more extensively, participants' attitudes and perceptions have changed dramatically. Regarding the instructors' resistance and skeptical attitudes towards the launch of the ER program, the results of current study is similar to that found in Byun (2010). This study focused on Korean EFL teachers' perspectives about their participation in an ER program. It found that although teachers were somewhat resistant to a given ER program prior to the research; at the end of the program, teachers became highly positive toward the ER program and recognized that linguistic benefits could be made available to the learners.

Unlike most of the studies located in the literature that utilized ER as part of in-class activities, this study asked students to read graded readers outside of the classroom as a partial course requirement. One of the main reasons this was done was to avoid additional workload for the teachers within the amount of limited lecture time. Additionally, this study was deemed different from most of others because the effectiveness of ER program was evaluated through a comparison of the students' reading scores. This study mainly looked at both teachers' and students' attitudes and perceptions toward the recently carried-out ER program along with the factors surrounding the program. To promote the ER program and to develop the students' reading habit, teachers were allowed to design any assessment formats necessary to evaluate their students reading outcomes. In the last teacher meeting, most teachers stated that they distributed written tests to the students related to the overall reading process. Yet, one teacher said that he requested that students role-play one of the stories they had chosen, and students learned a lot by practicing the lines; so, he was quite content that the students' pronunciation had also improved which gave an extra credit for the ER program. The teacher strongly suggested other teachers try out this method, and he has decided to continue to do this for participation in the next ER program.

There are several significant factors that affect students' attitudes toward the ER program found in this study. First, even though gender plays a minor role in the study, perhaps, if students were given the freedom to choose the books they wished to read, they might feel more motivated to read extensively (c.f. Asraf \& Ahmad, 2003; Paulson, 2006). Another noteworthy factor to be mentioned is that students from different colleges hold quite diverse perceptions of what constitutes an ER program. Students from the College of Management held the most positive attitudes toward the 
program from the rest of 7 colleges. It may be assumed that there is more English used as a medium of instruction for the courses offered in the College of Management; hence, students in that college are exposed to an immersive English environment and texts are more frequently in English so that the fear of reading in English is reduced. Besides, time spent weekly for reading the readers also played a considerable role in the study. Thus, it is confirmed that once the students are used to reading more extensively, they would further develop the reading habit gradually and that the resistance to reading in English would become diminished (c.f. Lemmer, 2010). As mentioned in the earlier section of this paper, Taiwanese education is quite test-centric. This means that the majority students do not want to spend time on reading materials which may be irrelevant to a test. This sort of situation results in students having a preference to read short texts (intensive reading) and disliking reading longer passages or readers (extensive reading). Apart from this, figures in Tables 1, 2, and 3 all indicate that students have great concerns related to reading for enjoyment. Hence, how to lead students from test-driven reading to reading for pleasure is a considerable challenge for teachers in Taiwan, especially for those teachers at the researched site. Even though teachers would love to create a stress-free / more enjoyable English learning environment for their learners, they must first meet the school's required English benchmark of having their students to pass CEFR B1 before graduation. Therefore, teachers are always placed in a dilemma when engaging in ER and opt for use of the grammar translation method and expense of time for test preparation in class.

The results of this study have provided the first stepping stone necessary to introduce extensive reading to both teachers and students and has gained certain recognition for the linguistic benefits of English teaching and learning through extensive reading efforts. Besides, considerable research has also proved and indicated the various kinds of assistance extensive reading for language learning can accomplish. Therefore, there is an urgent need to continuously promote extensive reading in the academic setting of a university campus. Better yet, it is necessary to completely change teachers' and students' negative feelings / hesitancy towards engaging in outside readings. Predominantly, the author would like to suggest that an ER program works better if school administrators indeed take this issue into account and support the idea of reading for pleasure and for gaining knowledge that is not merely for passage of a test and to obtain higher scores.

One issue derived from this current study is that students are so reluctant to purchase books. Although there are some collections in the library, it cannot meet the majority needs. It is becoming an issue nowadays at the researched university that students do want to buy books. Even though the importance of respecting the copy rights of authors' works is announced every time, students tend to neglect it and attend the class with copied materials or just share the books with others; or even worse, the students attend classes with empty hands. Hence, prior to promoting extensive reading, it is of great urgency to change students' attitudes / perceptions regarding the investment of their time and money in reading and education.

\section{References}

Apple, M. T. (2005). Extensive reading and the motivation to read: A pilot study. Doshisha Studies in Language and Culture, 8(1), 193-212.

Asraf, R. M., \& Ahmad, I. S. (2003). Promoting English language development and the reading habit among students in rural schools through the guided extensive reading program. Reading in a Foreign Language, 15(2), 83-102.

Bell, T. (2001). Extensive reading: Speed and comprehension. The Reading Matrix, 1(1), 1-13.

Byun, J.-H. (2010). Korean EFL Teacher's perspectives about their participation in an extensive reading program. Unpublished doctoral dissertation, University of Texas at Austin, Austin, USA.

Camiciottoli, B. C. (2001). Extensive reading in English: Habits and attitudes of a group of Italian university EFL Students. Journal of Research in Reading, 24(2), 135-153.

Cetin, Y., \& Brooks-Lewis, K. A. (2011). How do students feel about graded readers? International Journal of Business and Social Science, 2(23), 227-231.

Diane Schmitt, J. U \& Schmitt, N. (2014). Jumping from the highest graded readers to ungraded novels: Four case studies. Reading in a Foreign Language, 26(1), 1-28.

Educational Testing Service. (2014). 2013 Report on test takers worldwide: The TOEIC listening and reading test. Worldwide Report 2013. [Online] Available: https://www.ets.org/s/toeic/pdf/ww_data_report_unlweb.pdf

Grabe,W., \& Stoller, F.L. (2002). Teaching and researching reading. Essex, UK: Longman.

Greenberg, D., Rodrigo,V., Berry,A., Brinck,T. \& Joseph, H. (2006). Implementation of an extensive reading program with adult learners. Adult Basic Education, 16(2), 81-97.

He, M. (2014). Does extensive reading promote reading speed? The Reading Matrix, 14(1), 16-25.

Hill, D. R. (2001). Graded readers. ELT Journal, 55(2), 300-324.

Honeyfield, J. (1977). Simplification. TESOL Quarterly, 11(4), 431-440.

Horst, M. (2005). Learning L2 vocabulary through extensive reading: A measurement study. The Canadian Modern Language Review, 61(3), 355-382. 
Johnson, Y. (2012). Attitudes towards EFL learning and extensive reading in Japanese engineering students. Journal of Language and Culture of Hokkaido, 10, 65-81.

Juan, L., \& Cheng, C.-K. (2008). Using extensive reading to improve the learning performance and attitude of elementary school remedial students. English Teaching and Learning, 32(4), 41-83.

Kweon, S.-O., \& Kim, H.-R. (2008). Beyond raw frequency: Incidental vocabulary acquisition in extensive reading. Reading in a Foreign Language, 20(2), 191-215.

Lemmer, R. J. (2010). Do they see what we see?: Student reading habits and perceptions of extensive reading. Chugokugakuen Journal, 9, 1-6.

Maruyama, Y. (2009). Graded readers: Selecting an appropriate level for university EFL students. OnCue Journal, 3(1), 26-47.

Mason, B., \& Krashen, S. (1997a). Extensive reading in English as a foreign language. System, 25, 91-102.

Mason, B. \& Krashen, S. (1997b). Can extensive reading help unmotivated students of EFL improve? ITL Review of Applied Linguistics, 9(2), 78-84

Meng, F. (2009). Developing students' reading ability through extensive reading. English Language Teaching, 2(2), 132-137.

Modirkhamene, S., \& Gowrki, F. (2011). Extensive reading in relation to lexical knowledge \& reading fluency: Evidence from Iranian EFL learners. Modern Journal of Language Teaching Methods, 1(3), 5-23.

Morgado, N. F. (2009). Extensive reading: Student's performance and perception. The Reading Matrix, 9(1), 31-43. Nation, I.S.P. (2001). Learning vocabulary in another language. Cambridge, England: Cambridge University Press.

Nishino, T. (2007). Beginning to read extensively: A case study with Mako and Fumi. Reading in a Foreign Language, 19(2), 77-105.

Paris, S.G., Wasik, B.A. \& Turner, J.C. (1991). The development of strategic readers. In Barr, R., Kamil, M.L., Mosenthal, P., \& Pearson, P.D. (eds.), Handbook of Reading Research, Volume II. Mahwah, NJ: Lawrence Erlbaum.

Paulson, E. J. (2006). Self-selected reading for enjoyment as a college developmental reading approach. Journal of College Reading and Learning, 36(2), 51-58.

Pigada, M., \& Schmitt, N. (2006). Vocabulary acquisition from extensive reading: A case study. Reading in a Foreign Language, 18(1), 1-28.

Robb, T. N., \& Susser, B. (1989). Extensive reading vs skills building in an EFL context. Reading in a Foreign Language, 5(2), 239-251.

Robb, T. \& Kano, M. (2013). Effective extensive reading outside the classroom: A large-scale experiment. Reading in a Foreign Language, 25(2), 234-247.

Renandya, W.A., Sundara Rajan, B. R., \& Jacobs, G. M. (1999). Extensive reading with adult learners of English as a second language. RELC Journal, 30(1), 39-60.

Shen, M.-Y. (2008). EFL learners' responses to extensive reading: Survey and pedagogical application. The Reading Matrix, 8(2), 111-123.

Sheu, S. P-H. (2004). The effects of extensive reading on learners' reading ability development. Journal of National Taipei Instructors College, 17(2), 213-228.

Stoeckel, T., Reagan, N., \& Hann, F. (2012). Extensive reading quizzes and reading attitudes. TESOL Quarterly, 46(1), 187-198.

Taguchi, E., Takayasu-Maass, M. \& Gorsuch, G. J. (2004). Developing reading fluency in EFL: How assisted repeated reading and extensive reading affect fluency development. Reading in a Foreign Language, 16(2), 70-96.

Takase, A. (2007). Japanese high school students' motivation for extensive L2 reading. Reading in a Foreign Language, 19(1), 1-18.

Tran, A. (2006). Modified extensive reading for English-language learners. Reading Improvement, 43(4), 173-178.

Williams, E. (2007). Extensive reading in Malawi: Inadequate implementation or inappropriate innovation? Journal of Research in Reading, 30(1), 59-79.

Yamashita, J. (2008). Extensive reading and development of different aspects of L2 proficiency. System, 36, 661-672.

Yamashita, J. (2013). Effects of extensive reading on reading attitudes in a foreign language. Reading in a Foreign Language, 25(2), 248-263. 